\title{
INFORMATION SUPPORT OF THE REMOTE NITROGEN MONITORING SYSTEM IN AGRICULTURAL CROPS
}

\author{
Vitalii Lysenko, Oleksiy Opryshko, Dmytro Komarchuk, Natalia Pasichnyk, \\ Natalya Zaets, Alla Dudnyk
}

\author{
National University of Life and Environmental Sciences of Ukraine \\ st. Heroiv Oborony 12B, Kyiv, 03041, Ukraine, nubip.edu.ua \\ lysenko@nubip.edu.ua,ozon.kiev@gmail.com,dmitruyk@gmail.com,n.pasichnyk@nubip.edu.ua, \\ z-n@ukr.net, dudnikalla@nubip.edu.ua
}

Paper history:

Received 10 January 2018

Received in revised form 05 March 2018

Accepted 13 March 2018

Available online 31 March 2018

Keywords:

UAV;

monitoring

nutrition;

fertilizers;

drones.

\begin{abstract}
The article addresses issues on application of unmanned aerial vehicles (UAV) to monitor nitrogen nutrition through the example of wheat plants. The optical spectral range can be used to monitor exploitation of the UAV. It is recommended to develop specialized spectral indices for such equipment. The article provides calibration curves for nitrogen nutrition monitoring. In the created neural networks, the linear model is represented as a network without intermediate layers, which in the output layer contains only linear elements, the weight corresponds to the elements of the matrix, and the thresholds are the components of the shear vector. During the operation, the neural network actually multiplies the vector of inputs into the matrix of scales, and then adds a vector of displacement to the resulting vector. Results of the research show how to create the specialized Robot Plane Vegetation Indices adapted to technological capabilities of UAVs. It has been experimentally proved that input parameters that describe the state of agricultural plantations are regularly distributed. The average statistical characteristics for additive color RGB model is advisable to be the neural network input instead of large sample data volume.
\end{abstract}

Copyright (C) Research Institute for Intelligent Computer Systems, 2018. All rights reserved.

\section{INTRODUCTION}

Diagnosis of plants nutrition in agricultural production areas today has become extremely necessary among measures for sustainable development of crop. The high cost of fertilizers, fuel and lubricants, agricultural machinery, motor capacity cause high economic risks for making decisions about plant nutrition on production facilities. Nutrition most often provides for nitrogen fertilizer, so far as grain quality is determined primarily by protein, which is an integral part of nitrogen. Traditional land-based methods of determining the state of plants include colorimetric examination of farm plantations area using chemical reagents and require significant amount of time, so making immediate decisions on fertilization for each section of the field becomes impossible.

Some of the most promising technologies include non-destructive sensing of crops based on the analysis of reflection spectra that can be remotely fixed by sensors placed in aerial or satellite carriers. Industrial use of satellite monitoring systems for studying vegetation plants conditions has been carried out since the early 1970 s after the launch of Landsat Program in the USA. Due to the gained experience, implementation of satellite monitoring technologies has been extended and now several tens of satellite platforms are being operated providing data for more than two hundred different Vegetation Indices (VI) [1]. But along with advantages of satellite platforms for monitoring, there are certain physical limitations on their use, such as the lack of possibility to use them during cloudy weather, restrictions on the frequency band due to "transparency windows" of the atmosphere, etc. The solution to these problems should be the implementation of a stand-alone in-field remote sensing system (robot plane - RP), which has become affordable for farmers in recent decades. 
Thus, the aim of our research is to assess the possibilities of RP usage for nitrogen nutrition monitoring on the example of wheat plants.

\section{RELATIVE WORKS}

Placement of sensory equipment on the satellite platform caused certain technological aspects of its usage primarily as to wavelength range and techniques of radio frequency correction, which is required due to the sunlight instability. The direct use of existing techniques for RP is difficult or technologically impossible.

Today, to assess nitrogen nutrition such VI as NDVI (Normalized Difference Vegetation Index) [1] and NDNI (Normalized Difference Nitrogen Index) [2] are used, spectral red and near-infrared ranges $1510 \mathrm{~nm}$ and $1680 \mathrm{~nm}$ channels respectively are exploited. Usage of the infrared or "heat" range of satellite platforms is related to the less sensitive light changes. The optical range of $690-750 \mathrm{~nm}$ is used in multispectral method (Shadchin's method [3]), which is intended for low flying and ground platforms.

For radio frequency correction of satellite data natural optical templates (such as deep reservoirs, etc.) are used $[4,5]$. Regular light source is used for serial equipment (such as Raptor ACS-225LR) and VI NDVI is applied for calibration [6].

The use of a dedicated sensor is shown in [7-9].

These decisions are difficult to implement for RP because of the lack of natural optical templates in fields during low flying, and a large amount of power supply for the test sites lighting.

Proven solution for RP is the use of reflectance panels, which are placed directly on the field and are used to assess light $[10,11]$. In this document, the automatic control algorithm of multispectral camera parameters composed of a feed forward back propagation artificial neural network and an adaptive neuro-fuzzy inference system, yielded good reproducibility of results. However, the panel's dimensions must be sufficient for accurate identification and their use on an industrial scale is a significant economic and organizational task. Results of lighting calibration based on the system data from the image (EXIF data), are shown in [12].

However, in this case only incomplete data was displayed and calibration algorithm was not offered because the experiments were conducted during short time of one day.

Thus, from the literature analysis above we may see that today there are no standard methods of radio frequency calibration of RP that can be used on an industrial scale for the purpose of nitrogen nutrition remote diagnostics.
In real conditions plant nutrition during vegetation is carried out up to 9 times. And that period is not longer than a few days and therefore the best option is when the data from RP is quickly processed and transferred for being used by the appropriate equipment for making fertilizers. It is necessary to consider that plant diseases, the presence of pests can affect the spectral characteristics of plants. In particular, in the field conditions plant state assessment can be made by mobile sensors such as "Floratest". However, RP should be adapted to new data.

\section{PROPOSED APPROACH}

\subsection{STATIONARY EXPERIMENT}

Research was carried out during 2016 in the long-term stationary experiment of Department for Agricultural Chemistry and Quality of Plant Products, National University of Life and Environmental Sciences of Ukraine.

The long term experimental field was founded in 1956 and aimed at studying the fertilization of field crops. Geographically it is located in village Pshenychne, Vasylkiv district, Kyiv region (GPS Position $50^{\circ} 4$ '29.00 “N, 30 13' 21.00” E).

Within the stationary field, in addition to the basic options of the experiment the micro-field experiment for creating various backgrounds of plant nitrogen nutrition was conducted. Land area of the main experiment is $100 \mathrm{~m}^{2}$, areas of micro-field experiments $-10 \mathrm{~m}^{2}$, three-fold repetition (Fig. 1). Winter wheat varieties of Tsentylivka were studied.

To study the effect of different fertilizer standards such experiment options as 1) no fertilizer (control); 2) P80; 3) R80K80; 4) N60R80K80; 5) N90R120K120 were selected for winter wheat (normal N60R80K80 is recommended for this type of soil). Ammonium nitrate, ammophos and potassium chloride fertilizers were produced.

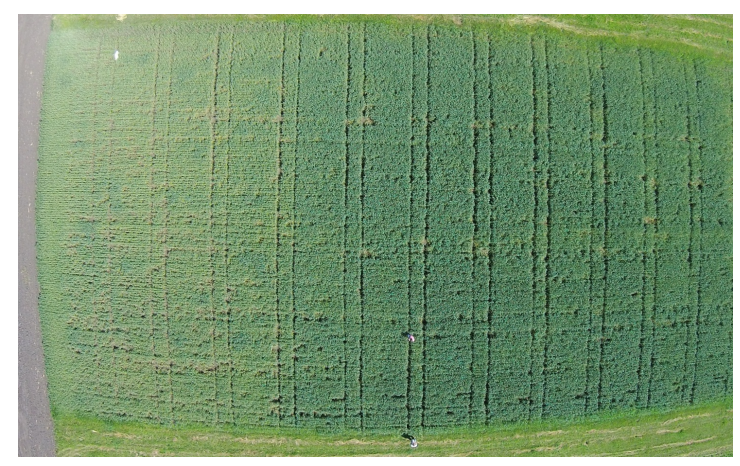

Fig. 1 - Stationary experiment "Agronomic Research Station”. 


\subsection{ANALYTICAL STUDIES OF PLANT NITROGEN NUTRITION}

Plants (aerial parts) were taken from each repetition option, washed under running water for cleaning dust and other dirt, dried on paper decks at room temperature to air-dry state. After air drying the material was crushed by scissors and dried in the oven at the temperature of $60^{\circ} \mathrm{C}$. The dried material was milled. After wet ashing the nitrogen content in plants was determined using photometric method with Nessler reagent.

\subsection{REMOTE SENSING SYSTEM}

Remote monitoring was conducted with the help of RP DJI Phantom 3+. Camera Model PHANTOM VISION FC200. Radio frequency calibration was performed on the basis of official data from exiff photo file jpeg format, and adjusting camera settings by the method described in [13-15]. Setting parameters of a digital camera are the following: Exposure Time - 1/1205; Aperture Value - 2.8; Light Source - Fine Weather; Color Space sRGB, ISO - 100. RP flight height was 100 meters above the surface.

Analysis of image data was carried out in the following sequence.

Output image file format was re-formatted from jpeg format to bmp, where the value of each color component was determined for each point of the image. The meaning of each color component was taken out for each point individually. The average value of each area on the micro-field experiments was calculated. Then areas whose values differed by more than $15 \%$ from the average were excluded (Fig. 2).

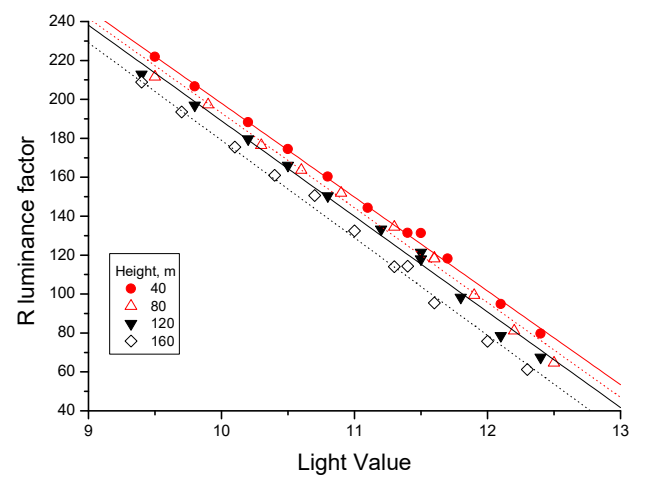

Fig. 2 - Relationship between red color component and light values at different monitoring altitude.

The procedure feasibility depends on the ground and the shadows of leaves that are on the image. Such areas availability on the image leads to errors which impact decreases with increasing distance from the field, i.e. a decrease in resolution (in the phase of wheat growth out of the tube). In experiments on selecting a mode of flight it was found that starting from the height of 100 meters a number of "rejection" areas of the field increases.

\section{RESEARCH RESULTS}

Analysis of the relationship between the values of the color components intensity and nitrogen content in the dry matter (Fig. 3) enabled to determine such relationship for the red and green components. Relationship between existing VI [1, 12], which use optical channels R, G, B, and nitrogen content in upper leaves of wheat (dry matter) were calculated on the basis of the experimental data (Table 1).

The calculations results show that the maximum coefficient of determination (Adj. $\mathrm{R}^{2}$ ) was obtained for the green and red color component, confirming the assumption [12] on the feasibility of development of specialized VI for RP.

Soil moisture, presence of cavity and hills also influence optical properties of plants. Standard tester type GreenSeeker takes into account these random factors [16], but appropriate adjustments to the calibration curves should be made quickly. Such tool as neural networks was suggested for solving this problem.

The resulting image was divided into parts with area of $10 \times 10$ meters for construction of a neural network. The size of the area was defined by technological dimensions of fertilization machine and may be adjusted depending on the type and brand of equipment.

Application package STATISTICA, developed by StatSoft was used for statistical data analysis. Variables Var1, Var2 and Var3 meet the numerical value of additive color model in RGB format under: Var1 - R, Var2 - G and Var3 - B.

After analyzing the input data distribution the three measures of central tendency are the same, i.e. average is almost equal to the median and mode (Var1- 106,8; 106; 102; Var2-129,1; 129; 121; Var3$75,6 ; 74 ; 73)$, and thus all incoming data is normally distributed [17]. That is, the average of statistical characteristics for additive RGB color model can be used as the input of the neural network and fully describe the nature of the image, that is being analyzed.

Classical models of statistical data analysis can be implemented using neural networks (NN) [18] because a definite relationship with continuous nonlinear function may be reproduced by layered network. That is, instead of the input display surface (phase) space, the resulting data with a hyper (AR), several hyper (TAR), or more hyperplane connected with one another (STAR), NN can make it arbitrary nonlinear display. 


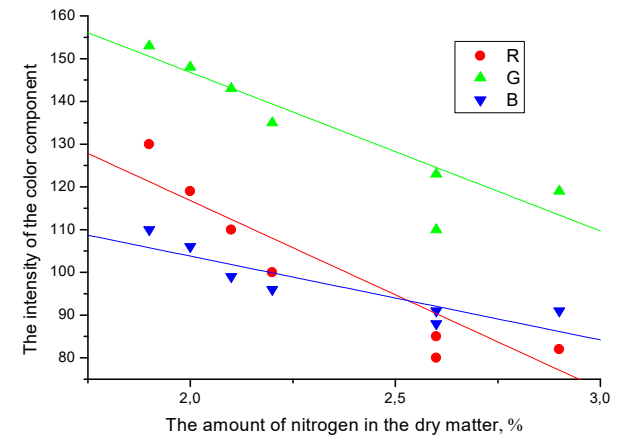

Fig. 3 - Relationship between red color component and light values at different monitoring altitudes.

Table 1. Relationship between nitrogen and VI

\begin{tabular}{|c|c|c|c|}
\hline № & Name & Formula & Adj. $\mathbf{R}^{\mathbf{2}}$ \\
\hline 1 & VARIgreen & VARIgreen $=(\mathrm{G}-\mathrm{R}) /(\mathrm{G}+\mathrm{R}-\mathrm{B})$ & 0,85 \\
\hline 2 & $\mathrm{RGR}$ & $\mathrm{RGR}=\mathrm{R} / \mathrm{G}$ & 0,79 \\
\hline 3 & $\mathrm{RI}$ & $\mathrm{RI}=(\mathrm{R}-\mathrm{G}) /(\mathrm{R}+\mathrm{G})$ & 0,81 \\
\hline 4 & NGRDI & $\mathrm{NGRDI}=(\mathrm{G}-\mathrm{R}) /(\mathrm{G}+\mathrm{R})$ & 0,81 \\
\hline 5 & $\mathrm{IO}$ & $\mathrm{IO}=\mathrm{R} / \mathrm{B}$ & 0,84 \\
\hline 6 & $\mathrm{IF}$ & $\mathrm{IF}=(2 * \mathrm{R}-\mathrm{G}-\mathrm{B}) /(\mathrm{G}-\mathrm{B})$ & 0,88 \\
\hline 7 & $\mathrm{I}$ & $\mathrm{I}=(\mathrm{R}+\mathrm{G}+\mathrm{B}) / 30,5$ & 0,82 \\
\hline 8 & $\mathrm{H}$ & $\mathrm{H}=\mathrm{atan}((2 \mathrm{R}-\mathrm{G}-\mathrm{B})(\mathrm{G}-\mathrm{B}) / 30,5)$ & 0,20 \\
\hline 9 & $\mathrm{GLI}$ & $\mathrm{GLI}=(2 * \mathrm{G}-\mathrm{R}-\mathrm{B}) /(2 * \mathrm{G}+\mathrm{R}+\mathrm{B})$ & 0,58 \\
\hline 10 & $\mathrm{IPCA}$ & $\mathrm{IPCA}=0.994(\mathrm{R}-\mathrm{B})+0.961(\mathrm{G}-$ & 0,83 \\
\hline 11 & R intensity & $\mathrm{B})+0.914(\mathrm{G}-\mathrm{R})$ & 0,89 \\
\hline 12 & G intensity & - & 0,94 \\
\hline 13 & B intensity & - & 0,82 \\
\hline
\end{tabular}

To synthesize and study appropriate NN the application package STATISTICA was used. Criterion - minimization of NN errors [17, 19, 21]. The advantage over similar developments is the implementation of the functional optimization unit of NN architecture that uses a linear approach and method for simulating "annealing" based on the probability distribution of Gibbs:

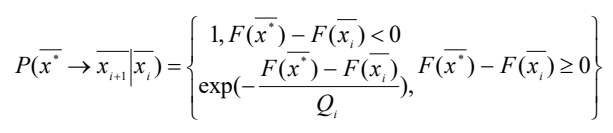

where $\mathrm{Q}_{\mathrm{i}}>0$ - elements random descending down to zero sequence.

We concidered the developed neural network as a mathematical model of parallel computing, which includes interacting simple processor elements artificial neurons; it was implemented to analyse optical images of plantation objects. The research aim is to develope, test and design artificial neural network for the plant state assessment.

For effective operation of the "Statistica Neural Networks" program, input data was divided into three blocks: studying, control, test (Fig. 4). The presence of three blocks is not obligatory, however, the "test" blocks improve the quality of further work of $\mathrm{NN}$, since it makes it possible to verify that there has been no "overfitting" of the network.

In terms of approximation, the simplest model will be a linear $[13-15,20,22]$, in which the approximating function is determined by a hyperplane. In the classification problem, the hyperplane is placed in such a way that it divides itself into two classes (linear discriminant function); in the regression problem, the hyperplane must pass through given points. The linear model is usually accepted by the equation:

$$
Y=X W+B
$$

where: $\mathrm{W}$ - matrix of weight of the network; B displacement vector.

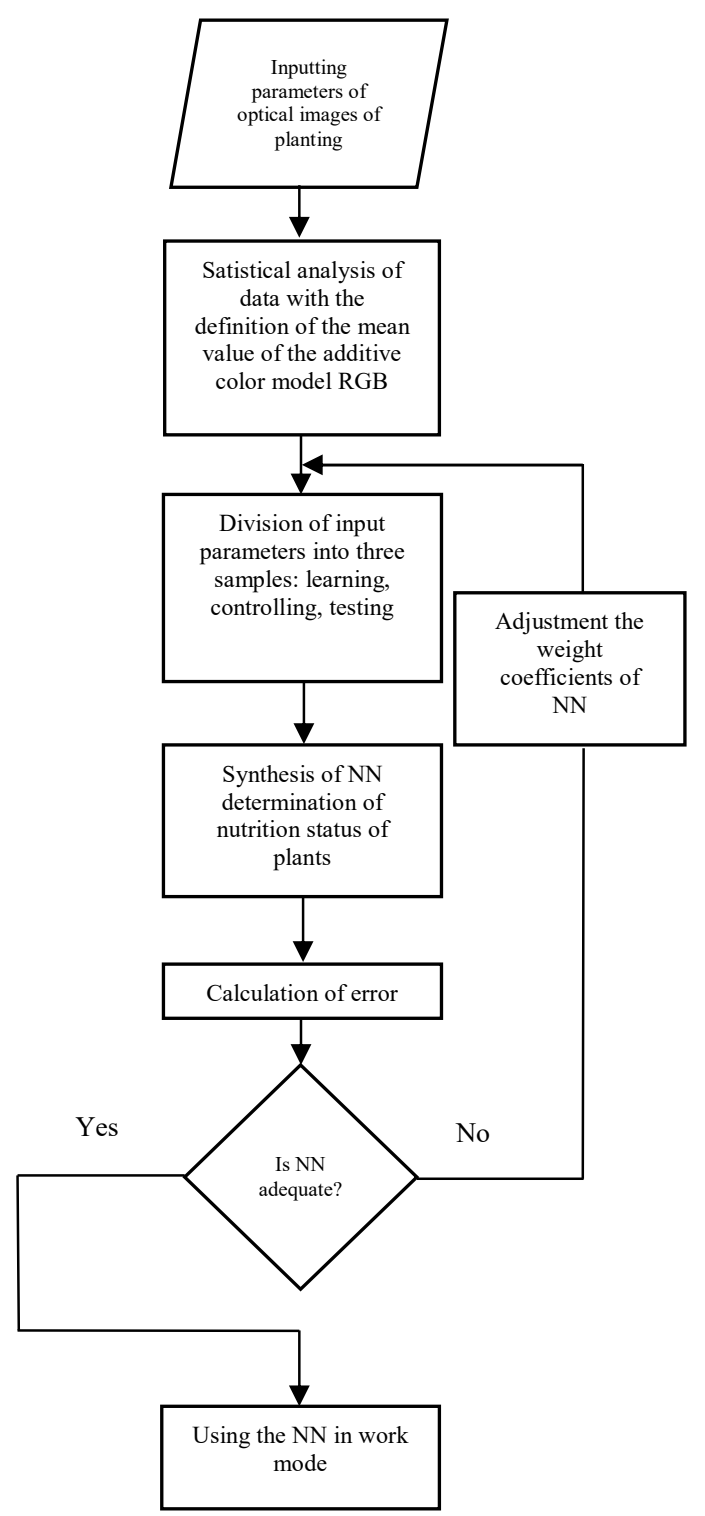

Fig. 4 - NN synthesis algorithm for determination of plant nutrition state. 
In the neural networks, the linear model is represented as a network without intermediate layers, which have only linear elements (elements with a linear activation function) in the output layer. The weight corresponds to the elements of the matrix, and the thresholds are the components of the shear vector. During the operation, the network actually multiplies the vector of inputs into the matrix of scales, and then adds a vector of displacement to the resulting vector. In accordance with the algorithm (see Fig. 5), a linear NN determination of the state of nutrition of planting plants is synthesized:

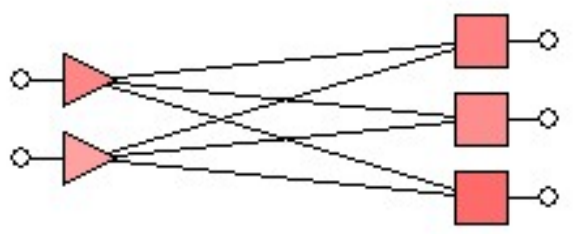

Fig. 5 - The architecture of the linear neural network.

Learning outcomes of the linear neural network:

- productivity: learning $-0,549$; control $-0,559$; test $-0,492$;

- errors: learning $-0,152$, control $-0,153$, test 0,154

In NN based on a multilayered perceptron, input signals passing through the synapses into three neurons are input to the inputs, creating a single layer of this network and generating three output signals:

$$
y_{i}=f\left(\sum_{i=1}^{n} x_{i} w_{i j}\right), j=1, \ldots, 3
$$

It is obvious that all weight coefficients of synapses of a single layer of neurons can be reduced to a matrix $W$, in which each element $W_{i j}$ sets the magnitude of the $i$ synaptic relation of the $j$ neuron.

Thus, the process occurring in a neural network can be written in a matrix form:

$$
Y=f(X W)
$$

where: $X$ i $Y$ - respectively, the input and output signal vectors (here and below under the vector is understood vector-string), $f(S)$ - the activation function.

In accordance with the $\mathrm{NN}$ arhitecture (Fig. 6) two networks of the type of multilayer perceptron are synthesized for determining the state of plant nutrition:

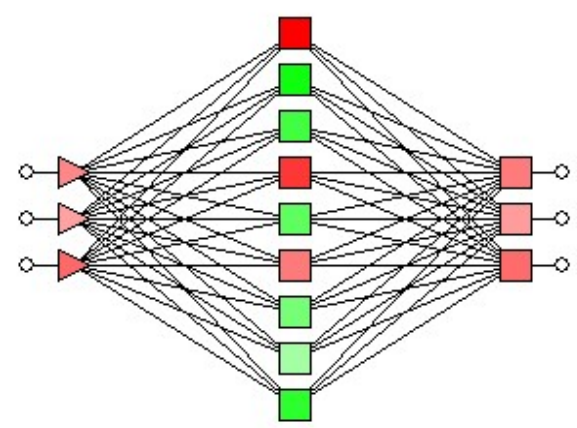

Fig. 6 - Architecture of NN based on multilayer perceptron.

Analyzing the results and schedules of the educational determination of the nutrition status of plants (Fig. 7 - Fig. 9), we resumed that the use of neural networks to assess the nutritional status of agricultural plantings is sufficiently precise and it can be implemented sed in the developed system of remote monitoring for agricultural crops.

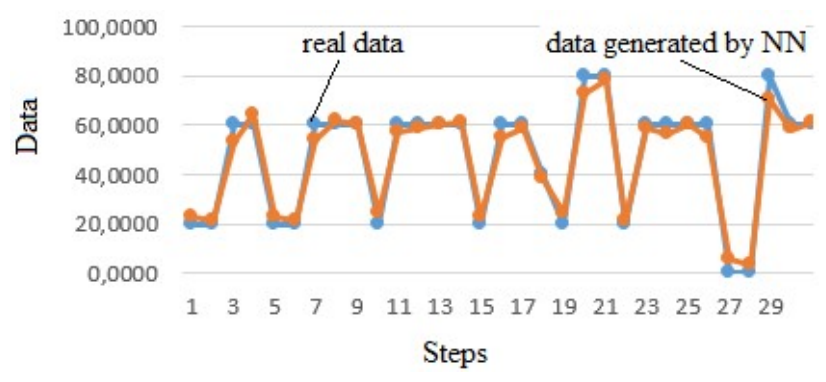

Fig. 7 - Schedule of educational determining the nitrogen supply state of plants by MLP 3:3-9-3:3.

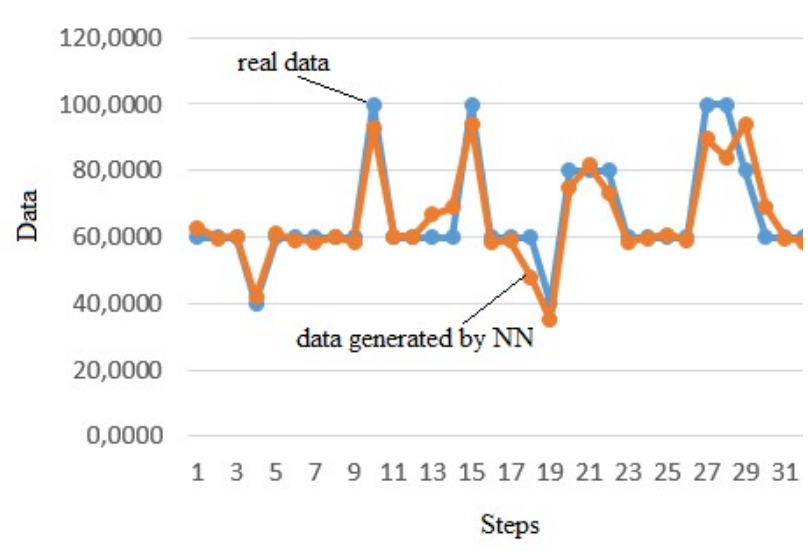

Fig. 8 - Schedule of the educational determining the potash plant nutrition by MLP 3:3-9-3:3. 


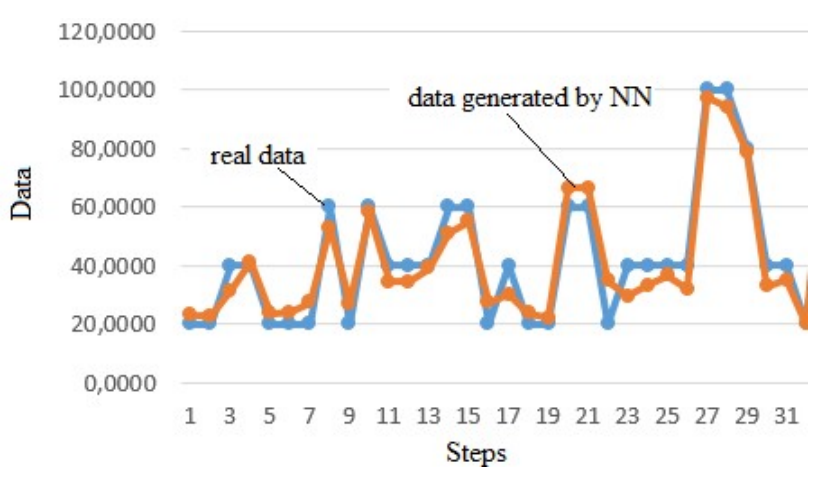

Fig. 9 - Schedule of educational determining the phosphorus plant nutrition by MLP 3:3-9-3:3.

As a result of solving an optimization problem the folloing $\mathrm{NN}$ were selected as the best: linear with three neurons in the input layer (mistakes: learning 0.12 , control -0.13 , test -0.127 ), multilayer perceptron with three neurons in the hidden layer (mistakes: learning: -0.07 , control $-0,076$, test 0.07), generalized regression network has 1,498 neurons in the hidden layer (mistakes: learning 0.03, control -0.03 , test -0.03$)$, Radial Basis Function (RBF) with 102 neurons in the hidden layer (mistakes: learning $-0,011$, control $-0,013$, test - 0.011), RBF with 154 neurons in the hidden layer (mistakes: learning -0.0109 , control -00127 , test -0.0115$)$.

Neural network type RBF showed the best results. RBF network with fewer neurons in the hidden layer was chosen for further research. Code in $\mathrm{C}++$ was used to develop the crop conditions remote monitoring system with RBF NN. The program code was compiled with the help of a standard compiler for free Unix-like GCC operating systems and implemented in the web-interface of the server, which allowed the use of the created $\mathrm{NN}$ remotely, directly in the production environment without high demand of the computing power of a personal computer. Consequently, we may conclude that neural networks should be used for analysis and image processing of agricultural crops to evaluate the plants nitrogen nutrition. This is a sufficiently accurate tool to be used in remote monitoring system.

\section{CONCLUSION}

It has been experimentally proved that in the optical range the color components intensity of the wheat upper leaves depends on nitrogen content in plants, due to the nutrition level.

The closest relationship between color intensity of wheat upper leaves and nitrogen content in plants is observed for green (coefficient of determination
Adj. R2 - 0,94) and red (Adj. R2 - 0,89) components.

Results of the research show how to create the specialized Robot Plane Vegetation Indices adapted to technological capabilities of UAVs. It has been experimentally proved that input parameters that describe the state of agricultural plantations are regularly distributed. The average statistical characteristics for additive color RGB model is advisable to be the neural network input instead of large sample data volume.

As a result neural network type RBF was synthesized as code in $\mathrm{C}++$ that can be used in the developed remote web monitoring system of agricultural plants conditions.

\section{REFERENCES}

[1] T. Ahamed, L. Tian, Y. Zhang, K. Ting, "A review of remote sensing methods for biomass feedstock production," Biomass \& Bioenergy, vol. 35, no. 7, pp. 2455-2469, July 2011.

[2] I. Herrmann, A. Karnieli, D. Bonfil, Y. Cohen, V. Alchanatis, "SWIR-based spectral indices for assessing nitrogen content in potato fields," International Journal of Remote Sensing, vol. 31, no. 19, pp. 5127-5143, January 2010.

[3] T. M. Shadchina, "Elaboration of theoretical bases and methods of the remote sensing of winter wheat crops using the high resolution spectrometry," Manuscript, Thesis for Dr. Sci (Biol.) by speciality 03.00.12 - Plant Physiology, Institute of Plant Physiology and Genetics, National Academy of Sciences of Ukraine, Kyiv, 1999.

[4] L. S. Bernstein, S. M. Adler-Golden, R. L. Sundberg, et al., "Validation of the QUick Atmospheric Correction (QUAC) algorithm for VNIR-SWIR multi- and hyperspectral imagery," Proceedings of SPIE, vol. 5806, pp. 668-678, 2005.

[5] K. Soudani, G. Hmimina, N. Delpierre, J.-Y. Pontailler, M. Aubinet, D. Bonal, B. Caquet, A. de Grandcourt, B. Burban, C. Flechard, D. Guyon, A. Granier, P. Gross, B. Heinesh, B. Longdoz, D. Loustau, C. Moureaux, J.-M. Ourcival, S. Rambal, L. Saint André, E. Dufrêne, "Ground-based network of NDVI measurements for tracking temporal dynamics of canopy structure and vegetation phenology in different biomes," Remote Sensing of Environment, vol. 123, pp. 234-245, 2012.

[6] D.W. Lamb, D.A. Schneider, M.G. Trotter a, M.T. Schaefer, I.J. Yule, "Extended-altitude, aerial mapping of crop NDVI using an active optical sensor: A case study using a Raptor ${ }^{\mathrm{TM}}$ 
sensor over wheat," Computers and Electronics in Agriculture, vol. 77, pp. 69-73, 2011.

[7] J. Zhou, L.R. Khot, H.Y. Bahlol, R. Boydston, P. N. Miklas, "Evaluation of ground, proximal and aerial remote sensing technologies for crop stress monitoring," IFAC-PapersOnLine, vol. 49, no. 16, pp. 22-26, 2016.

[8] Y. Kondratenko, O. Gerasin, \& A. Topalov, "A simulation model for robots slip displacement sensors," International Journal of Computing, vol. 15, issue 4, pp. 224-236, 2016.

[9] M. Patil, T. Abukhalil, S. Patel, \& T. Sobh, "Ub swarm: hardware implementation of heterogeneous swarm robot with fault detection and power management," International Journal of Computing, vol. 15, issue 3, pp. 162-176, 2016.

[10] M. Herrero-Huerta, D. Hernández-López, P. Rodriguez-Gonzalvez, D. GonzálezAguilera, J. González-Piqueras, "Vicarious radiometric calibration of a multispectral sensor from an aerial trike applied to precision agriculture," Computers and Electronics in Agriculture, vol. 108, pp. 28-38, 2014.

[11] H. Xiang, L. Tian, "An automated stand-alone in-field remote sensing system (SIRSS) for inseason crop monitoring," Computers and Electronics in Agriculture, vol. 78, no. 1, pp.18, 2011.

[12] M. M. Saberioona, M. S. M. Amina, A. R. Anuarb, A. Gholizadehc, A. Wayayokd, S. Khairunniza-Bejoda, "Assessment of rice leaf chlorophyll content using visible bands atdifferent growth stages at both the leaf and canopy scale," International Journal of Applied Earth Observation and Geoinformation, vol. 32, pp. 35-45, 2014.

[13] V. Lysenko, O. Opryshko, D. Komarchyk, N. Pasichnyk, "Drones camera calibration for the leaf research," Scientific Journal NUBiP, no. 252, pp. 61-65, 2016.

[14] V. Lysenko, D. Komarchuk, O. Opryshko, N. Pasichnyk, N. Zaets, "Determination of the not uniformity of illumination in process monitoring of wheat crops by UAVs," in Proceedings of the 4th International Conference on Problems of Infocommunications. Science and Technology (PIC S\&T), pp. 265-267, 2017. [Online]. Available: ieee.org/document/8246394/

[15] V. Lysenko, D. Komarchuk, O. Opryshko, N. Pasichnyk, N. Zaets, A. Dudnyk, "Usage of flying robots for monitoring nitrogen in wheat crops," in Proceedings of the 9th IEEE International Conference on Intelligent Data Acquisition and Advanced Computing Systems:
Technology and Applications (IDAACS'2017), 2017, vol. 1, pp. 30-34. [Online]. Available: http://ieeexplore.ieee.org/document/8095044/

[16] J. Enciso, M. Maeda, J. Landivar, J. Jung, A. Chang, "A ground based platform for high throughput phenotyping," vol. 141, pp. 286291, 2017.

[17] V. Borovikov, Statistica. Data analysis on computer, 2-nd edit, St. Petersburg: Piter, 2003, 688 p.

[18] V. P. Lysenko, V. M. Reshetyuk, V. M. Shtepa, N. A. Zaets, Artificial Intelligence: Fuzzy Logic, Neural Networks, Fuzzy Neural Networks, Genetic Algorithm, Kyyiv: NUBiP Ukraine, 2014, $341 \mathrm{p}$.

[19] M. Arbib, The Handbook of Brain Theory and Neural Networks, London: MIT Press, 2003, $1309 \mathrm{p}$.

[20] J. Hertz, A. Krogh, R. Palmer, Wstep do Teorii Obliczen Neuronowych, Wyd. II, Warszawa: WNT, 1995.

[21] A.R. Barren, "Approximation and estimation bounds for artificial neural networks," Machine Learning, vol. 14, pp. 115-133, 1994.

[22] S. Samarasinghe, Neural Networks for Applied Sciences and Engineering: from Fundamentals to Complex Pattern Recognition, CRC Press, 2006.

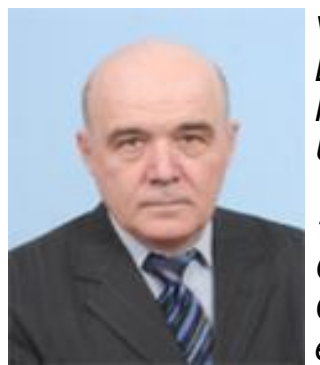

Vitalii Lysenko is a Head of the Department of Automation and Robotic Systems of NULES of Ukraine. PhD., Professor. He was born on February 11, 1950 in the village of. Mlyev, Gorodischensky district of Cherkasy region. $\mathrm{He}$ is an electrical engineer, graduated from the faculty of electrification Ukrainian Labor Red Banner of the Agricultural Academy in 1972. In 1979 he defended his Ph.D. thesis in the specialty 05.13.07 - Automation of control processes on the theme "Development and research of circuits and technical means for electric charging and automatic aerosol spraying of medicinal preparations of poultry complexes".

He has 263 publications, including 12 textbooks and manuals, 6 monographs, 15 copyright certificates and patents, over 100 scientific articles in professional journals. 


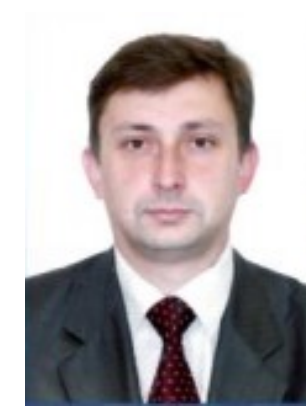

Oleksiy Opryshko is an associate professor of the Department of Automation and Robotic Systems of NULES of Ukraine.

He was born on April 27, 1974 in Kyiv. He graduated from the State Academy of Light Industry of Ukraine in 1996. In 2003 he defended his Ph.D. thesis on the theme "Increase of operational reliability of the system of protective destruction of electrical installations of livestock farms". Since 2001 he has been working at the Center for Computer Technologies Training and Information Center of the University, since 2003 - at the Department of Automation.

$\mathrm{He}$ is an author of 3 patents, 25 articles, 5 methodical developments, a mentor of the academic group. Scientific interests - information and computer-integrated technologies, ecological systems.

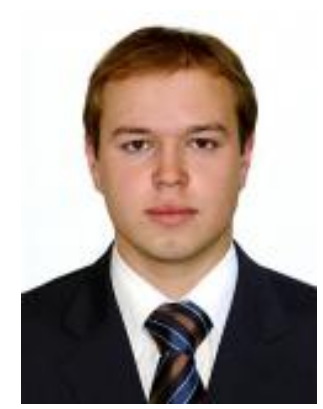

Dmytro Komarchuk is an associate professor of the Department of Automation and Robotic Systems of NULES of Ukraine, PhD.

He was born on 07.10.1987 in Mala Vilshanka, Bila Tserkva district, Kyiv region. $\mathrm{He}$ graduated in 2009 from National University of Bioresources and Natural Resources of Ukraine, majoring in electrification and automation of agriculture, engineer-researcher.

In 2014 he defended his thesis in specialty "Electrical Engineering Systems and Systems".

He published 34 scientific papers, including 18 articles, 6 declarative patents for invention, 10 abstracts at scientific conferences.

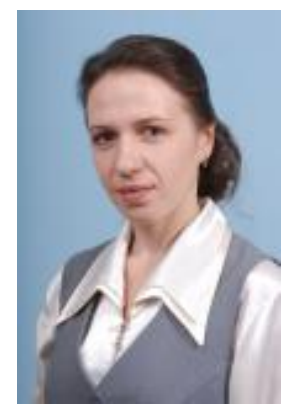

Natalia Pasichnyk is an associate professor of the Department of Agricultural Chemistry and Quality of Plant Products of NULES of Ukraine, PhD.

She graduated from National Agrarian University, specialty agroecology, qualification scientist agronomist, 1998. The

theme of the candidate's thesis: "Efficiency of using coal-fox ("Tecos-3") in growing carrot dining on dark gray podzolized soils of the Northern Forest-steppe of Ukraine", specialty 06.01.04 - Agrochemistry, 2002. Sphere of scientific interests: optimization of conditions of nutrition and fertilization of corn, application of water-soluble fertilizers, systems of remote sensing of the state of crops.

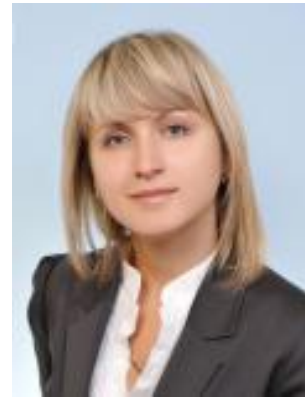

Natalya Zaets is an associate professor of the Department of Automation and Robotic Systems of NULES of Ukraine, PhD.

She was born on September 18, 1981 in Andrushivka, Zhytomyr region. She graduated with honors in 2004 from the National University of Food

Technologies, specializing in "Automated Process Management". In 2008 she defended a dissertation for the degree of a candidate of technical sciences in the specialty 05.13.07 - automation of control processes on the theme "Automated control of the column by a diffusion installation using the principles of coordination and adaptation". Since September 2009 she has been working as a senior lecturer in the Department of Automation and Robotics Systems.

She published 29 scientific papers, including 10 articles, 2 declarative patents for invention, 17 abstracts at scientific conferences. Scientific and pedagogical directions: problems of synthesis of adaptive regulators; systemic task of coordination of subsystems of technological complexes; design of food production automation systems; design of computer-integrated technologies; simulation of technological processes; informational support of food production.

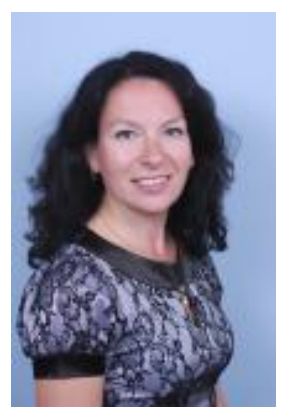

Alla Dudnyk is an associate professor of the Department of Automation and Robotic Systems of NULES of Ukraine, PhD.

She was born on March 27, 1986 in the city of Jizzakh, Republic of Uzbekistan. In 2008 she graduated with honors from the National University of Life and Environmental Sciences of Ukraine, majoring in "Automated Control of Technological Processes". From 2010 till 2013 she had been a graduate student of the Department of Automation and Robotics Systems. acad. I. I. Martynenko. In 2014 she defended her thesis on "Automated management of the process of growing tomatoes in greenhouses with the forecasting of external natural disturbances" and received a scientific degree of the candidate of technical sciences in the specialty 05.13.07 - Automation of control processes. She is the author of 35 scientific and methodological works, among which 3 patents of Ukraine to the utility model.

The direction of scientific research - modern intellectual control systems, energy conservation in closed-ground buildings, development of energy management systems for agro-industrial objects. 